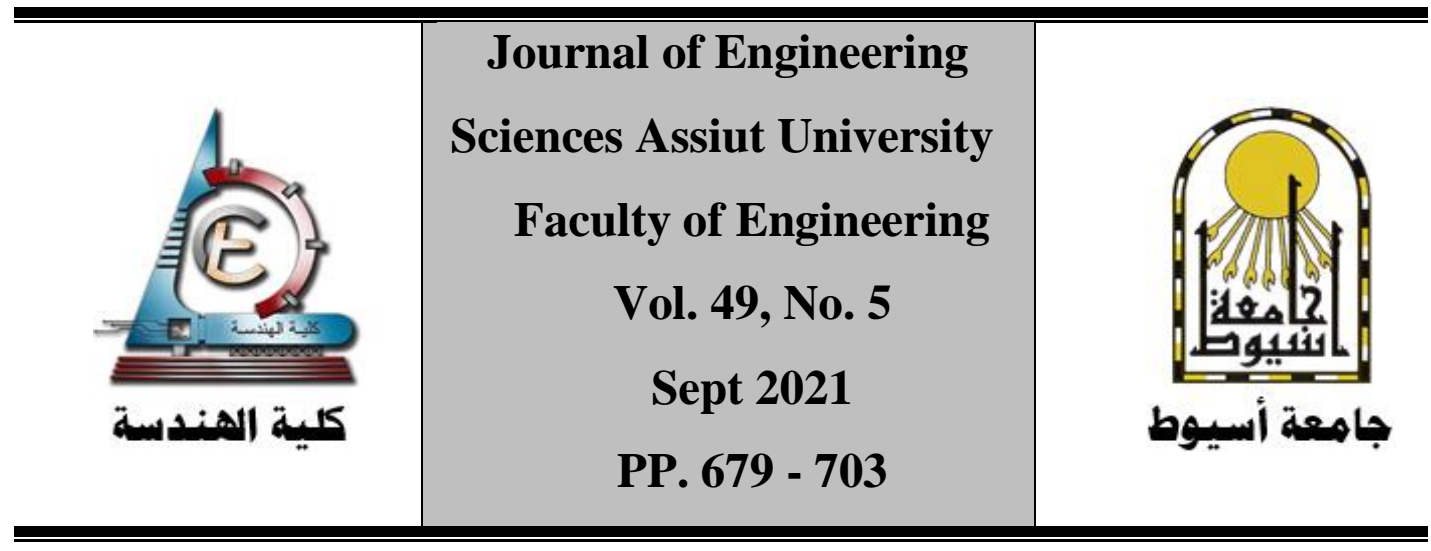

\title{
PERFORMANCE INVESTIGATION OF HOT- AND WARM- ASPHALT MIXTURES MODIFIED WITH SUPERPLAST
}

\author{
Ghada S. Moussa ${ }^{1}$, Ibrahim Sallam ${ }^{2}$, and Hassan Younis ${ }^{3}$ \\ ${ }^{1}$ Associate. Prof. Civil Engineering Department, Faculty of Engineering, Assiut \\ University, Egypt.Ghada.moussa@aun.edu.eg \\ ${ }^{2}$ Project Manager General Nile Company for Roads and Bridges, Assiut, Egypt. \\ d336862@gmail.com \\ ${ }^{3}$ Prof. Civil Engineering Department, Faculty of Engineering, Assiut University, \\ Egypt.younes@aun.edu.eg
}

Received 23 June 2021; Revised 3 August 2021; Accepted 11 August 2021

\begin{abstract}
Moisture and stripping damages are the most prevalent cause of defects of both Hot-Mix Asphalt (HMA) and Warm-Mix Asphalt (WMA). Adhesion between aggregates and bitumen is a crucial factor that affects such defects. Various methods, such as incorporating additives, have strengthened the asphalt mixture's resistance to moisture and stripping. This paper aimed to experimentally investigate the effect of including a low-cost polymer additive (Superplast) into HMA and WMA mixtures. For this goal, a 60/70 penetration grade bitumen was used. For preparing the WMA mixtures, Showax was employed with percentages of $2,3,4,5$, and $6 \%$ by weight of bitumen. Polymer modified mixtures (HMA and WMA) were prepared by adding 3\%, 4, and $5 \%$
\end{abstract}


of Superplast by weight of the binder. Performance characterizations of the unmodified and Superplast-modified mixtures include stiffness, moisture damage resistance, and bonding. These characteristics were evaluated via Marshall, Lottman, and Double Punching tests, respectively. Results revealed that incorporating Superplast improved the adhesion between bitumen and aggregates, which ultimately led to an increase in the stiffness and moisture resistance of both HMA and WMA. Moreover, Superplast-modified WMA mixtures exhibited the best moisture and stripping resistance performance compared to Superplast-modified HMA and other unmodified mixtures.

Keywords: Hot-mix Asphalt, Warm-mix Asphalt, Pavement, Polymer, Moisture Susceptibility, Stripping, Lottman Test, Double Punch Test

\section{Introduction}

Based on mixing and compaction temperatures, asphalt mixtures can be classified into three alternatives: hot-mix asphalt (HMA), warm-mix asphalt (WMA), and cold-mix asphalt (CMA). Warm-mix asphalt (WMA) is an energy-saving and environmentally friendly alternative compared to conventional HMA since it can be mixed and compacted at lower temperatures, therefore, reducing energy consumption and exhaust emissions while maintaining good road performance [1, 2]. WMA can be produced in three ways: by using organic additives such as Aspha-min, Showax, and Sasobit, by using emulsified asphalt, and by using foamed asphalt technologies. Many studies were performed for WMA investigation, with the majority of them focusing on road efficiency validation, additive dose determination, and construction technology $[\underline{3}, \underline{4}]$. The lower temperature rate associated with WMA mixing and compaction may have adverse effects. It may reduce the oxidation level of the utilized asphalt binder and consequently increase the fatigue and oxidation resistance [5-8]. On the other hand, it may cause a reduction in the aggregate/binder adhesion, i.e., stripping [9-12]. Some previous studies showed that WMA could have similar or better performance properties compared to the conventional HMA [13-18]. However, other studies showed that the performance of HMA outperforms that of WMA, particularly in the resistance against rutting and moisture damage [19-28]. 
Showax additives have two completely different functions that depend on the physical phase of the asphalt binder. The first function of wax can be observed when the asphalt binder is in the liquid phase at temperatures above $100{ }^{\circ} \mathrm{C}$. Above this temperature; the wax reduces the viscosity of the binder. The second function of wax can be observed in the middle and low-temperature ranges, where the asphalt binder is in the colloidal phase or solid phase, increasing the asphalt binder's viscosity. However, low, and high viscosity values at high and medium temperatures are more desirable in terms of lowering construction temperatures and improving resistance to rutting. The effect of the wax depends on the chemical composition and rheological properties of the asphalt binder, the crystallinity of the wax, the range of applied temperature, and the amount of wax [29].

Utilizing polymers modified asphalt (PMA) for roadway construction has earned remarkable attention due to their superior performance, including thermal-crack resistance, moisture susceptibility, and rutting resistance [30-36]. However, polymer-modified asphalt mixtures require high mixing and compacting temperatures, increasing energy consumption and exhaust emissions [37]. Wu and Montalvo presented a literature review about incorporating ten different polymers into HMA mixtures [38]. They concluded that polymers incorporation improved stiffness, rutting, and fatigue resistance. However, the performance of PMA mixtures tended to be temperature-dependent, i.e., they performed better at high temperature (rutting resistance) and worse at low temperature (fatigue cracking resistance). Kim et al. evaluated the performance of PMA binder containing warm mix asphalt additives (Alpha-min and Sasobit). They reported that incorporating WMA additive improved binder rutting resistance but reduced fatigue cracking resistance [39].

Most WMA modification studies focused on incorporating high-cost materials such as; thermoplastic-elastomer polymers (styrene butadiene styrene (SBS) and styrene-butadiene rubber (SBR)), anti-striping agent, and hydrated lime [40-44]. While their reported results revealed performance enhancements, their application for a wide field of pavement construction was not practical due to their high cost.

To this end, if a low-cost polymer can be incorporated into WMA technology, the benefit of polymers while reduced mixing- and 
compaction- temperatures can be attained. However, such integration needs more investigation. Therefore, this study aimed to investigate the effect of incorporating a low-cost polymer additive (Superplast) into both HMA and WMA mixtures then compare their performance.

\section{Materials and testing methods}

\subsection{Materials}

Asphalt with a penetration grade of $60 / 70$ and a specific gravity of 1.02 from Suez refinery was used as the control asphalt; its physical properties are shown in Table 1. The coarse and fine aggregates used in this study were crushed dolomite stone and siliceous sand obtained from a quarry in El Kawamel City. The mineral filler employed in this study is a cement fume dust with 3.8 specific gravity. The course, fine aggregate, and mineral filler gradation are shown in Tables 2, 3, and 4, respectively.

Table 1: Physical properties of the control Asphalt Binder

\begin{tabular}{cccc}
\hline Test & Standard test method & Results & Specification \\
\hline Penetration, & ASTM D5/D5M-20 [45] & 69.6 & $60-70$ \\
\hline Softening & ASTM D36/D36M-20 [46] & 47 & $45-55$ \\
\hline
\end{tabular}

Table 2: Gradation of Coarse Aggregate

\begin{tabular}{ccc}
\hline Sieve & \multicolumn{2}{c}{ Passing (\%) } \\
\cline { 2 - 3 } $\begin{array}{c}\text { Size } \\
(\mathbf{m m})\end{array}$ & Pin & Pin \\
\hline $\mathbf{2 5 . 4}$ & 2 & 1 \\
\hline $\mathbf{1 9 . 0}$ & 100 & 100 \\
\hline $\mathbf{9 . 5 2}$ & 78 & 100 \\
\hline $\mathbf{4 . 7 5}$ & 0 & 80 \\
\hline $\mathbf{2 . 3 6}$ & -- & 9 \\
\hline
\end{tabular}

Table 3: Gradation of Sand

\begin{tabular}{cl}
\hline Sieve Size $(\mathbf{m m})$ & Passing \\
\hline $\mathbf{4 . 7 5}$ & 100 \\
\hline $\mathbf{2 . 3 6}$ & 100 \\
\hline $\mathbf{0 . 6}$ & 52 \\
\hline $\mathbf{0 . 3}$ & 16 \\
\hline $\mathbf{0 . 1 5}$ & 4 \\
\hline $\mathbf{0 . 0 7 5}$ & 2 \\
\hline
\end{tabular}


683

JES, Assiut University, Faculty of Engineering, Vol. 49, No. 5, Sept. 2021, pp. 679-703

Table 4: Gradation of Mineral Filler

\begin{tabular}{cc}
\hline Sieve Size $(\mathbf{m m})$ & Passing \\
\hline $\mathbf{0 . 3}$ & 100 \\
\hline $\mathbf{0 . 1 5}$ & 96 \\
\hline $\mathbf{0 . 0 7 5}$ & 86 \\
\hline
\end{tabular}

For achieving a low-level temperature for producing WMA, a wax additive, namely Showax is used. Showax is the commercial name of organic additive (fatty acid amid wax). It is one of the essential additives used in warm asphalt mixtures to improve workability and low asphalt mixing temperatures. A lowcost plastomeric polymer additive; Superplast, is a compound of formed Ethylene-vinyl acetate (EVA), Low-density polyethylene (LDPE), and other polymers with low molecular weight and a medium fusion point. The datasheet for the physical and mechanical properties of the used Showax and Superplast are presented in Tables 5 and 6, respectively, as listed in the manufacturer's brochure (Shorouk Chemical Company - Egypt) [47]. Fig. 1. Illustrates the utilized Showax and Superplast particles.

Table 5: Physical properties of the Showax[47]

\begin{tabular}{ccccc}
\hline Additives & $\begin{array}{c}\text { Melting } \\
\text { Point }\left({ }^{\circ} \mathbf{C}\right)\end{array}$ & $\begin{array}{c}\text { Brookfield } \\
\text { viscosity at } \mathbf{1 6 0} \\
(\mathbf{c P})\end{array}$ & $\begin{array}{c}\text { Penetration } \\
\mathbf{a t ~ 2 5}^{\circ} \mathbf{C}(\mathbf{0 . 1} \\
\mathbf{m m})\end{array}$ & $\begin{array}{c}\text { Size } \\
(\mathbf{m m})\end{array}$ \\
\hline Showax & $100-120$ & 15 & $2-7$ & $1-2$ \\
\hline
\end{tabular}

Table 6: Physical properties of Superplast[47]

\begin{tabular}{llllll}
\hline Additives & Aspect & $\begin{array}{l}\text { Softening } \\
\text { point }\end{array}$ & $\begin{array}{l}\text { Fusion } \\
\text { point }\end{array}$ & Melt Index & $\begin{array}{l}\text { Size } \\
(\mathbf{m m})\end{array}$ \\
\hline Superplast & $\begin{array}{l}\text { black/grey } \\
\text { granules }\end{array}$ & $150^{\circ} \mathrm{C}$ & $160^{\circ} \mathrm{C}$ & $1 \div 5$ & 4 \\
\hline
\end{tabular}

\subsection{Methods}

To attain the goal of the study, the following stages were considered; first, binder samples (unmodified and modified) were prepared. The second stage considered designing HMA and WMA mixers (unmodified and modified) and determining optimum binder contents using the Marshall Mixture design method according to ASTM D6927 [48]. Finally, all prepared mixtures were experimentally evaluated. Mixtures' stiffness (hardening), moisture damage resistance, and stripping susceptibility were assessed via the Marshall test, modified Lottman test, and double punching test, respectively $[49,50]$. All experimental 
tests in the third and fourth phases were performed on three replicates for each group of mixtures. Fig. 2 displays the outline of the laboratory work undertaken.

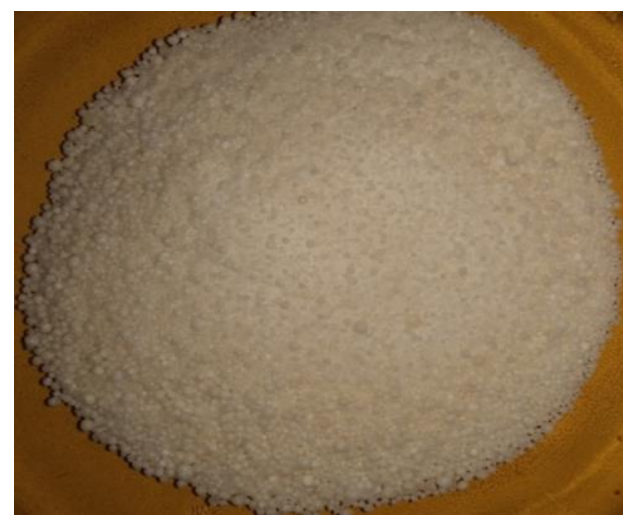

(a)

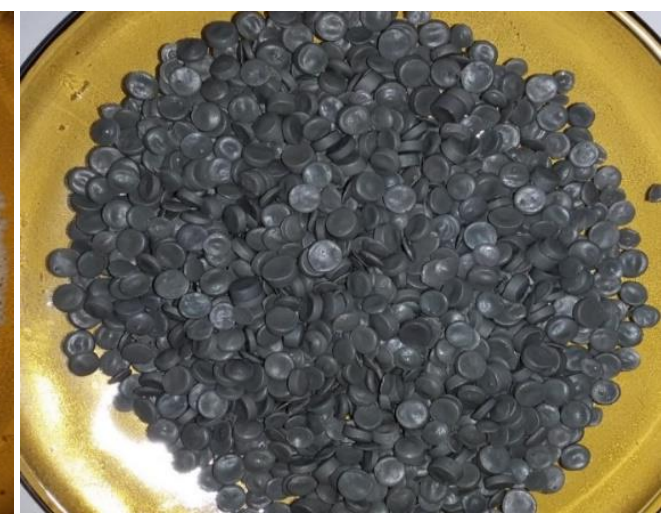

(b)

Fig. 1. Utilized additives; (a) Showax; (b) Superplast

\subsubsection{Sample preparation}

In this study, a wet method was used to prepare the asphalt binders containing Showax additives. For this purpose, the Showax was added to a pre-heated control binder at $140{ }^{\circ} \mathrm{C}$ and stirred until complete dissolution is attained. The dosage of the employed Showax was $2 \%, 3 \%, 4 \%, 5 \%$, and $6 \%$ by weight of asphalt binder. Then, WMA mixtures were prepared using these binders. The blending temperature of the employed Showax was $140^{\circ} \mathrm{C}$ according to the manufacturer's recommendations[47].

For incorporating Superplast, a dry process was used. Superplast was incorporated into a pre-heated aggregate at $180^{\circ} \mathrm{c}$ until Superplast coated aggregate, then it was mixed with hot bitumen $\left(160^{\circ} \mathrm{C}\right)$. The incorporated dosage of Superplast was 3\%, 4\%, and 5\% by weight of the binder, based on the manufacturer's recommendations[47]. Then blending calculations of the conventional wearing surface layer of (4C) gradation according to Egyptian specifications were performed [51].

\subsubsection{Mixtures Design}

Conventional Asphalt mixture: In this study, the $4 \mathrm{C}$ dense gradation for wearing course (surface mixes) according to the Egyptian specifications was selected (ECP)[52]. To achieve this gradation, the following blend was used: $25 \%$ pin $2,29 \%$ pin $1,39 \%$ sand, and $7 \%$ mineral filler. The specification limits of the $4 \mathrm{C}$ gradation and the design gradation (Asphalt 
Mix Design) of the investigated mixture are shown in Fig. 3.

Marshall mix design following AASHTO T 245 was used to define the optimum asphalt content (OAC) of a control asphalt mix using conventional asphalt.

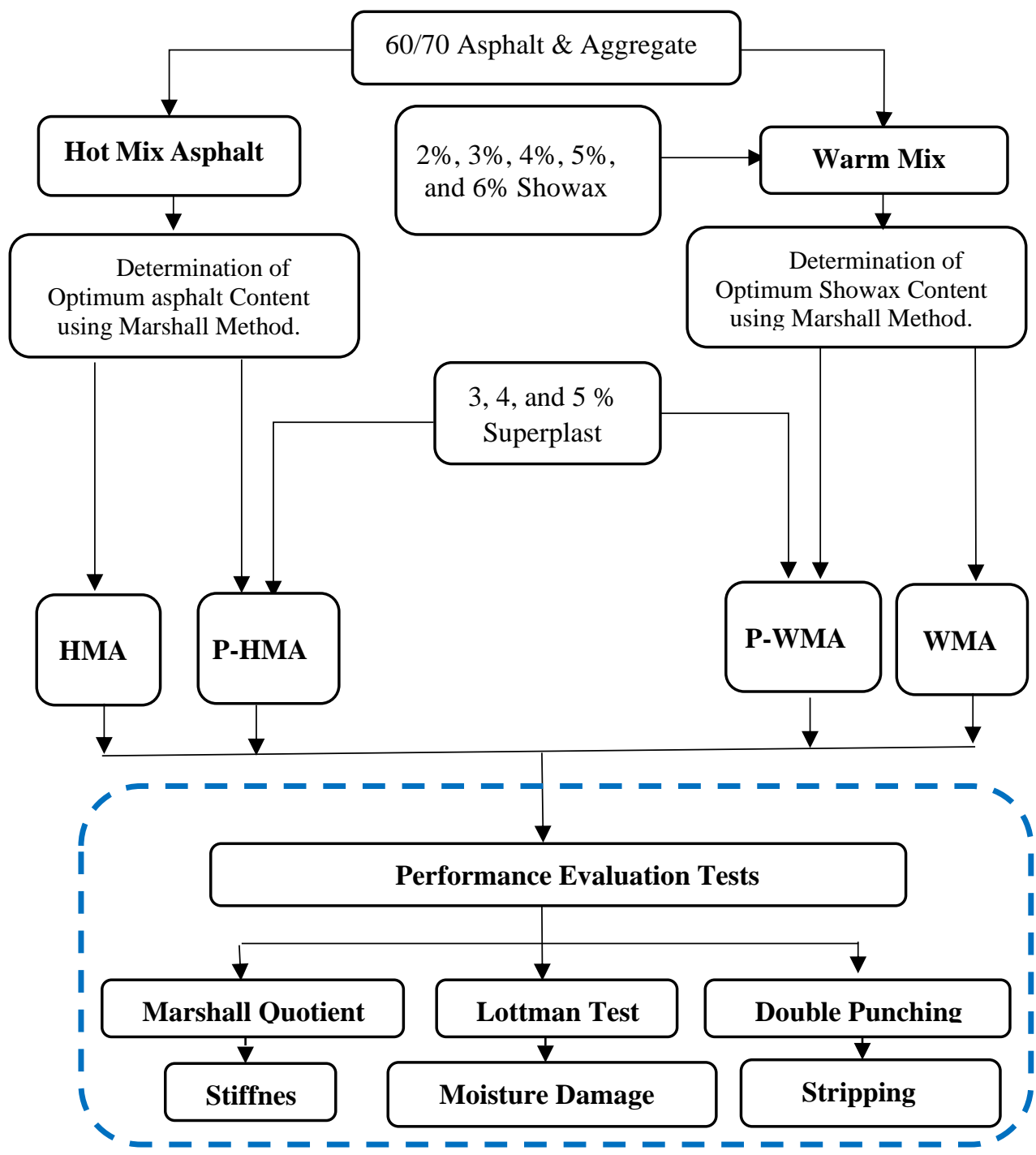

Fig. 2. Research Methodology 
-Desighn 4C Wearing Surfuce

$\longrightarrow$ Specification Lower Limit

-Specification Upper Limit

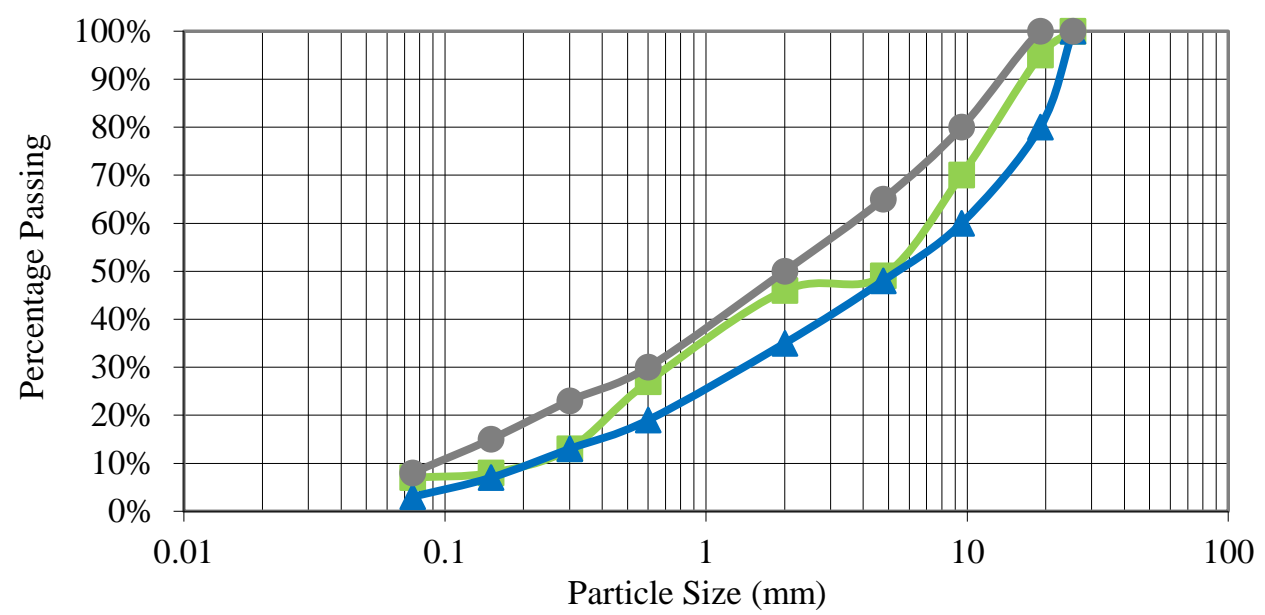

Fig. 3. Job Mix Formula and the Specification Limits

Warm Mix Asphalt (WMA): For preparing WMA, the 60/70 asphalt was heated to $140{ }^{\circ} \mathrm{C}$ then Showax was added as described early. After that, the binder at $140{ }^{\circ} \mathrm{C}$ was added to the designed aggregate blend[47]. It should be noted that the mixing time was longer than the mixing time for HMA mixtures.

\subsubsection{Performance Characterization Tests}

Stiffness Test: For evaluating the prepared mixtures' stiffness (rigidity), Marshall Quotient (MQ) value was estimated using the Marshall Test results (ASTM D 6927). MQ is a well-known indicator representing the asphalt mixture's stiffness and its rutting tendency [53-56]. According to ASTM D-6927, for each mixture, three Marshall specimens were immersed in water for $30-\mathrm{min}$ at $60^{\circ} \mathrm{C}$ just before testing. Then, samples were loaded at a $50.8 \mathrm{~mm} / \mathrm{min}$ loading rate in the Marshall testing machine until the failure (maximum load). For each mixture, three replicants were tested. By dividing the average failure load value by the associated deformation value, the Marshall Quotient (MQ) is estimated for that mixture.

Moisture Susceptibility: The modified Lottman test is considered a standard test for assessing the moisture resistance of asphalt mixes. In this study, a modified Lottman test was conducted on both conventional and modified mixtures samples to determine the effect of moisture on 
the asphalt mixture's tensile strength following AASHTO T283-14 [57]. Six Marshall Samples were prepared for each mix with $7 \pm 1 \%$ air void ratios. Three samples were stored in an air bath at $25^{\circ} \mathrm{C}$ for at least four hours before testing (dry set). The other three samples were immersed in a water bath at $60 \pm 1.0^{\circ} \mathrm{C}$ for 24 hours then stored in another water bath at $25^{\circ} \mathrm{C}$ for 2 hours before testing (wet set). Then the indirect tensile strength (ITS) and the tensile strength ratio (TSR) were calculated as follows[57],

$$
\mathrm{ITS}=\frac{2 P}{\pi H D}
$$

$\mathrm{TSR}=\frac{I T S_{w e t}}{I T S_{d r y}} \times 100$

Where, $\mathrm{P}(\mathrm{kN})$ is the failure load, $\mathrm{H}(\mathrm{mm})$ is sample thickness, D $(\mathrm{mm})$ is sample diameter, $\operatorname{ITS}_{\mathrm{dry}}(\mathrm{kPa})$ is the average indirect tensile strength for the first group samples, and $\operatorname{ITS}_{\text {wet }}(\mathrm{kPa})$ is the average indirect tensile strength for the second group samples.

Stripping susceptibility: Stripping susceptibility (deboning) of conventional and-modified mixtures is assessed using the double punching (DP) test. This test procedure was advanced at the University of Arizona by Jimenoz (1974), which was used for measuring the stripping of the binder from the aggregate [49]. Then several studies have reported this test [34, 58-61]. Marshall samples were used for the test, and three specimens were conditioned by placing them in water at $60 \pm 1{ }^{\circ} \mathrm{C}$ for 30 minutes. The specimen was centered between two cylindrical steel punches $(2.54 \mathrm{~cm}$ in diameter $)$ perfectly aligned one over the other and then loaded at a rate of $(2.54 \mathrm{~cm} /$ minute $)$ until failure, as shown in Fig.4. Then the maximum resistance was recorded. The punching strength can be calculated as follows.

$\sigma=\frac{\mathrm{p}}{\pi\left(1.2 \mathrm{bH}-a^{2}\right)}$

where, $\sigma(\mathrm{Pa})$ is punching shear stress, $\mathrm{p}(\mathrm{N})$ is the maximum load, a $(\mathrm{mm})$ is the radius of punch, $\mathrm{b}(\mathrm{mm})$ is the specimen radius, and $\mathrm{H}=2 \mathrm{~h}$ 
$(\mathrm{mm})$ is the specimen height.

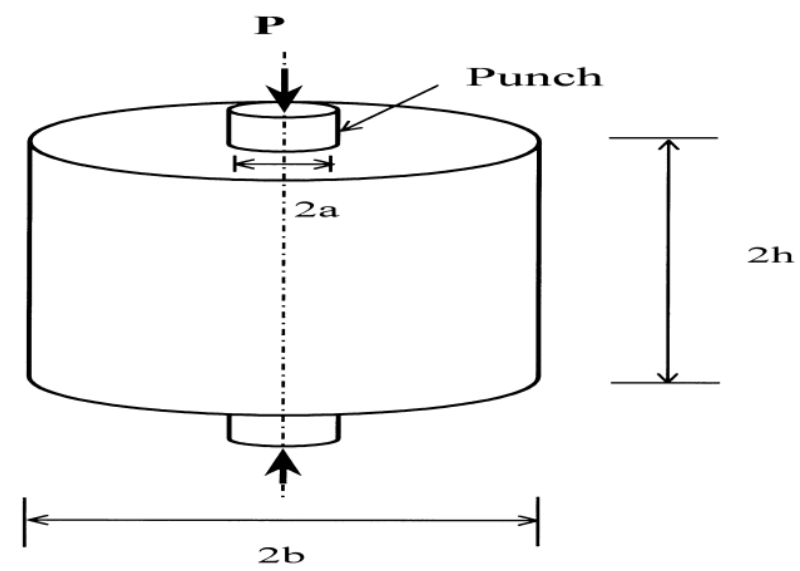

Fig. 4. Double punch test Setup [62]

\section{Results and analysis}

\subsection{Hot Mix Asphalt Mixtures}

\subsubsection{Conventional HMA}

Five different percentages of AC (4.0, 4.5, 5.0, 5.5, and 6.0) were mixed with the blended aggregate. A total of 15 Marshall Plugs were prepared (three plugs at each AC percentage). The volumetric properties of each sample were determined, and the samples were loaded in the Marshall Equipment to determine the stability and flow at $60^{\circ} \mathrm{C}$.

The optimum Asphalt content (OAC) was determined based on the asphalt institute method as the average of three values (asphalt content at maximum stability, maximum density, and $4 \%$ air voids in hot mix asphalt). Then this asphalt content was used to make sure it meets the mixed design criteria. The conventional asphalt mixture was designed by the Marshall method, and the properties of the asphalt mixture are presented in Error! Not a valid bookmark self-reference.. 
Table 8: Marshall Mix Design Properties

\begin{tabular}{llcc}
\hline Parameter & Value & \multicolumn{2}{c}{ Asphalt Institute[63] } \\
\cline { 2 - 4 } & & Minimum & Maximum \\
\hline Marshall bulk density (t/m $\mathbf{m}^{\mathbf{3}}$ ) & 2.34 & --- & ---- \\
\hline Theoretical Maximum Specific Gravity, Gmm & 2.44 & & \\
\hline Stability (kg) & 1588 & 900 & \\
\hline Flow (mm) & 3.05 & 2 & 4 \\
\hline Air voids (AV) (\%) & 4.14 & 3 & 5 \\
\hline Voids in mineral aggregates (VMA) (\%) & 15.62 & 15 & ---- \\
\hline Voids filled with binder (VFB) (\%) & 73.46 & 65 & ---- \\
\hline Asphalt cement $(\boldsymbol{\%})$ & 5.0 & --- & ---- \\
\hline
\end{tabular}

\subsubsection{Polymer modified HMA}

Fig. 5 presents the average Marshall test results and the corresponding volumetric properties for the convention HMA and Superplast modified HMA (P-HMA) in comparison. Based on the results, adding Superplast to the HMA increased the stability, and the maximum value attained at 4\% Superplast (4\%P-HMA).

From Fig. 5-b, it can be observed that with the increase in modifier content, there is a change in the flow values with the observation that there is no specific trend of increase or decrease. The stability and flow values for all modified mixtures satisfied the design standards for the Egyptian code's surface layer with heavy traffic, i.e., more than $900 \mathrm{~kg}$ and within 4.06 to $2.03 \mathrm{~mm}$ for the stability and flow, respectively [52]. Based on Fig. 5-c, adding Superplast to the asphalt mixture reduced the bulk density compared to the convention HMA. The highest bulk density was attained when incorporating $5 \%$ of Superplast (5\%P-HMA). Fig. depicts the variation of the percentage of air voids (AV \%), the percentage of voids in mineral aggregate (VMA \%), and the percentage of voids filled with aggregate (VFA \%) values of the convention HMA and Superplast-modified HMA with different Superplast contents. Adding Superplast to the HMA did not significantly affect the AV\%, VMA\%, and VFA\%. The air voids values for all mixtures satisfied the specifications, i.e., 3 to 5\% [52]. Based on Marshall's results the optimum content of Superplast was remarked to be $4 \%$. 


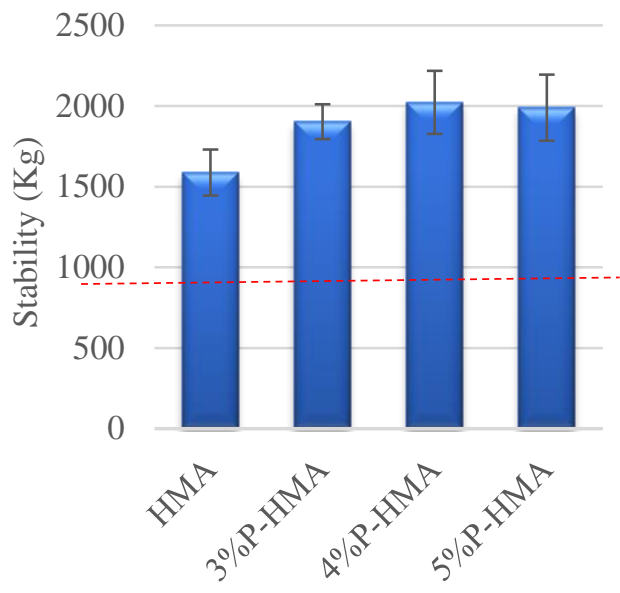

(a)

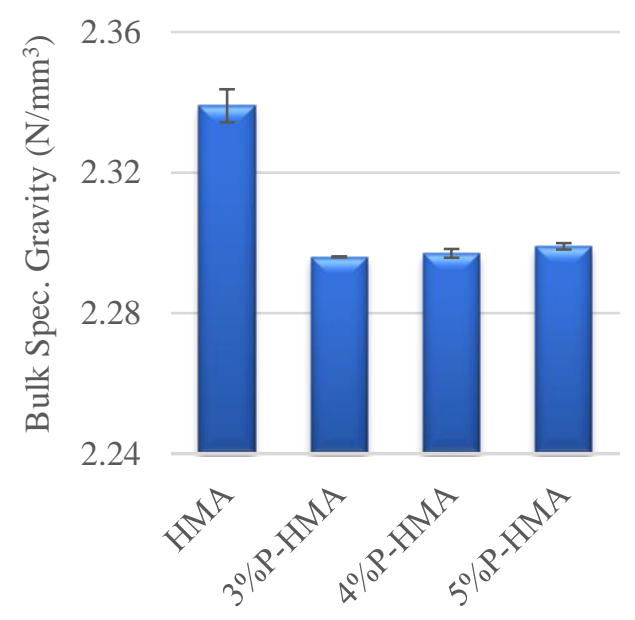

(c)

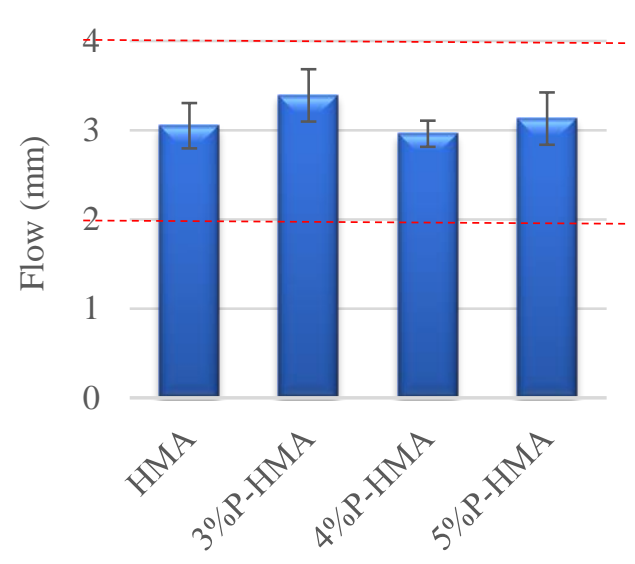

(b)

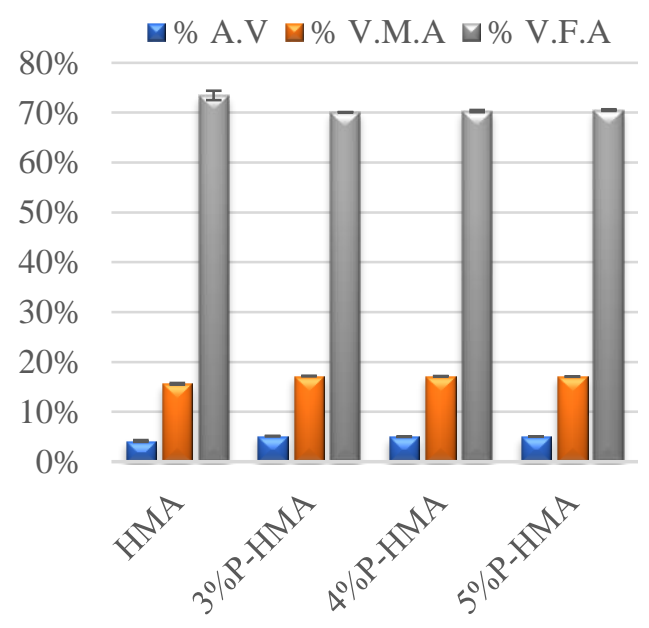

(d)

Fig. 5. Marshall results of HMA and Superplast-modified HMA mixtures; (a) stability, (b) flow, (c) bulk specific gravity, and (d)volumetric properties

\subsection{Warm Mix Asphalt (WMA)}

\subsubsection{Convention WMA}

The average Marshall test results as well as their corresponding volumetric properties for WMA with incorporating 2\%, 3\%, 4\%, 5\%, and 6\% Showax are depicted in Fig.6. At all Showax contents, the stability and the flow values were within the permissible limits according to Egyptian specifications [52]. Error! Reference source not found. shows the effect of employing different percentages of Showax on the specific gravity of WMA. In the beginning, there was a gradual decrease in the specific gravity values with increasing Showax content 
till $4 \%$ of Showax, and then the values increased to their most enormous value at $6 \%$. The effect of using different percentages of Showax on VFA\%, AV\%, and VMA\% values of WMA is shown in Error! Reference source not found.. The values of the AV\% and the (VMA\%) decreased with the increase in the percentage of Showax in the mixture. On the contrary, the values of (VFA\%) increased with the increase in the percentage of Showax. Generally, the air voids content was within the range of $3 \%$ to $5 \%$ for all samples. Based on the results presented in Error! Reference source not found., the optimum content of Showax was $5 \%$ of the weight of the asphalt.

\subsubsection{Polymer modified WMA}

Error! Reference source not found. presents the average Marshall test results and the corresponding volumetric properties for the convention WMA and Superplast modified WMA (P-WMA) while employing 5\% Showax and 3\%, 4\%, and 5\% Superplast. From Error! Reference source not found., it was observed that the stability values increased with the increasing percentage of Superplast, as the Superplast significantly improved stability in all ratios compared to the control mix. The maximum stability was attained at 5\% Superplast. In general, the flow values of all mixtures with different Superplast ratios are within the Egyptian specifications except 4\% Superplast as shown in Error! Reference source not found.. Error! Reference source not found. shows specific gravity values for WMA and P-WMA. Adding Superplast into WMA increased mixtures specific gravity value and the maximum value was attained at 3\% Superplast. Moreover, the effect of using different percentages of Superplast on VFA\%, AV\%, and VMA\% values of WMA is shown in Error! Reference source not found.. The values of the AV\% and the (VMA \%) slightly decreased with increasing the percentage of Superplast. On the contrary, the values of (VFA \%) increased with the increase in the percentage of Showax. Generally, the air voids content was within the range of $3 \%$ to $5 \%$ for all samples. Based on the presented results, the best P-WMA performance was attained when incorporating 5\% of Superplast, i.e., 5\%P-WMA. 


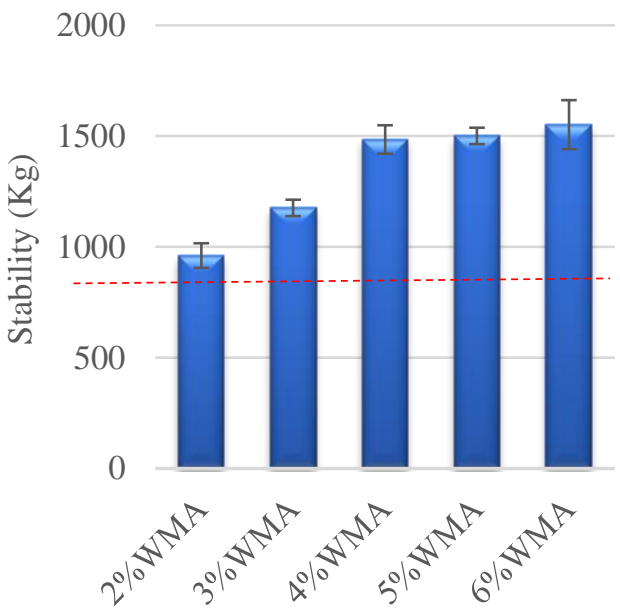

(a)

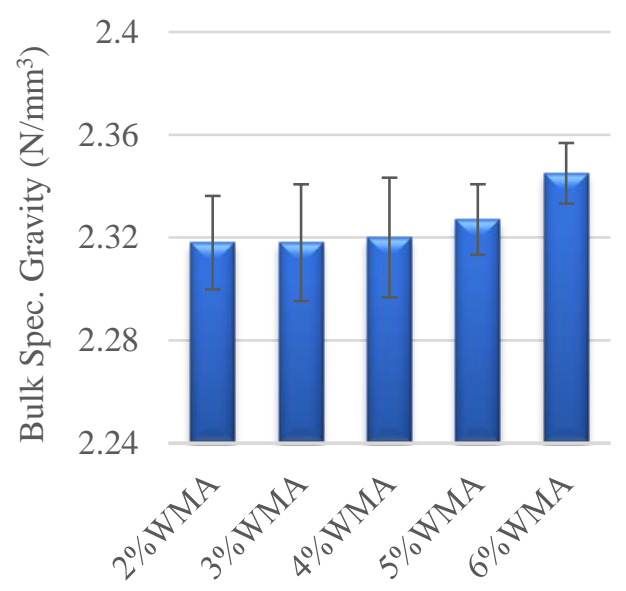

(c)
5

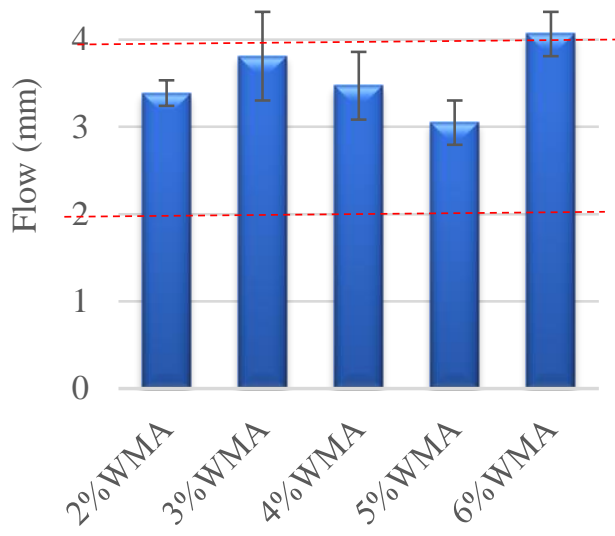

(b)

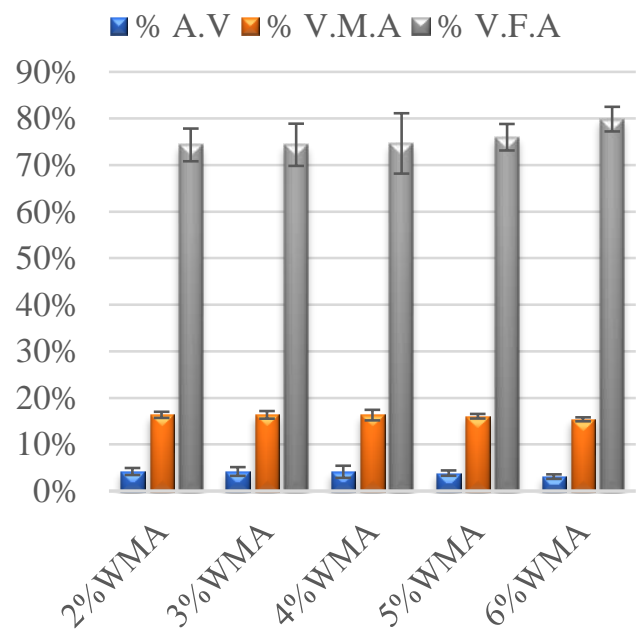

(d)

Fig. 6. Marshall results of WMA mixtures; (a) stability, (b) flow, (c) bulk specific gravity, and (d)volumetric properties 
693

JES, Assiut University, Faculty of Engineering, Vol. 49, No. 5, Sept. 2021, pp. 679-703

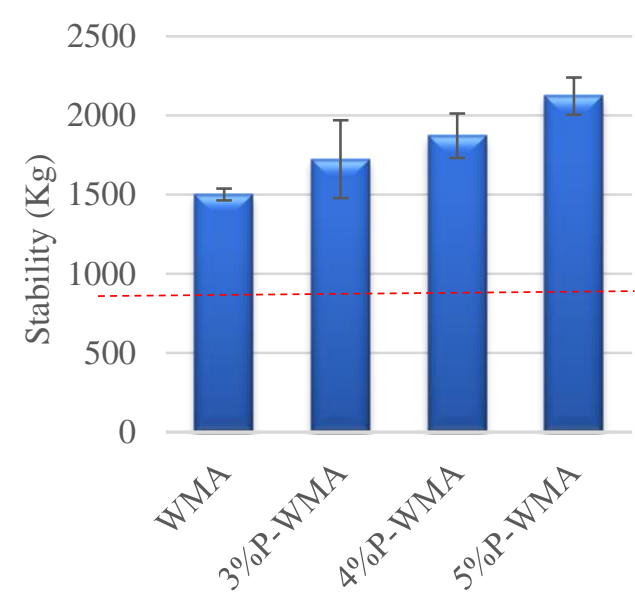

(a)

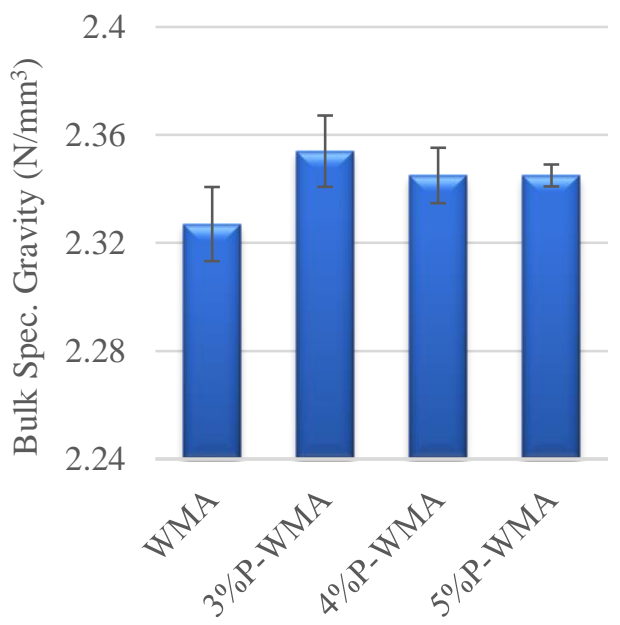

(c)

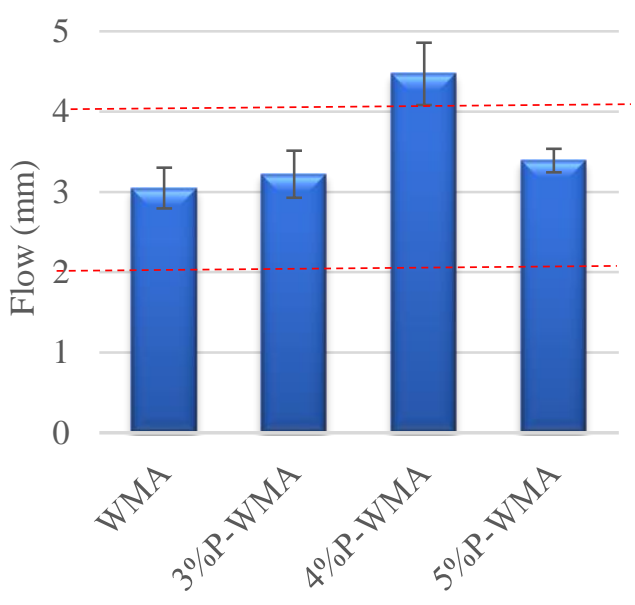

(b)

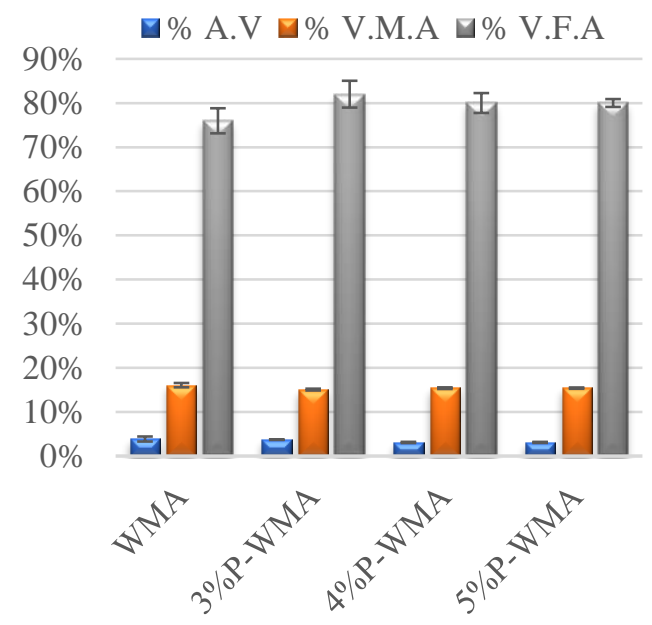

(d)

Fig. 7. Marshall results of WMA and Superplast-modified WMA mixtures; (a) stability, (b) flow, (c) bulk specific gravity, and (d)volumetric properties

\subsection{Performance Evaluation}

This section presents the results of the performance evaluation tests conducted on the four mixtures: HMA, Superplast-modified HMA (PHMA), WMA, and Superplast-modified WMA (P-WMA).

\subsubsection{Stiffness Test}

For evaluating the mixtures' stiffness (rigidity), Marshall Quotient (MQ) value was obtained using the Marshall Test results 
(ASTM D 6927). MQ calculated from dividing the stability over the flow, which can be used as an indication for the mixture's rutting resistance. The higher MQ values indicate higher mixtures' stiffness and consequently higher resistance to permanent deformation i.e., rutting [64]. The outcomes of the test results

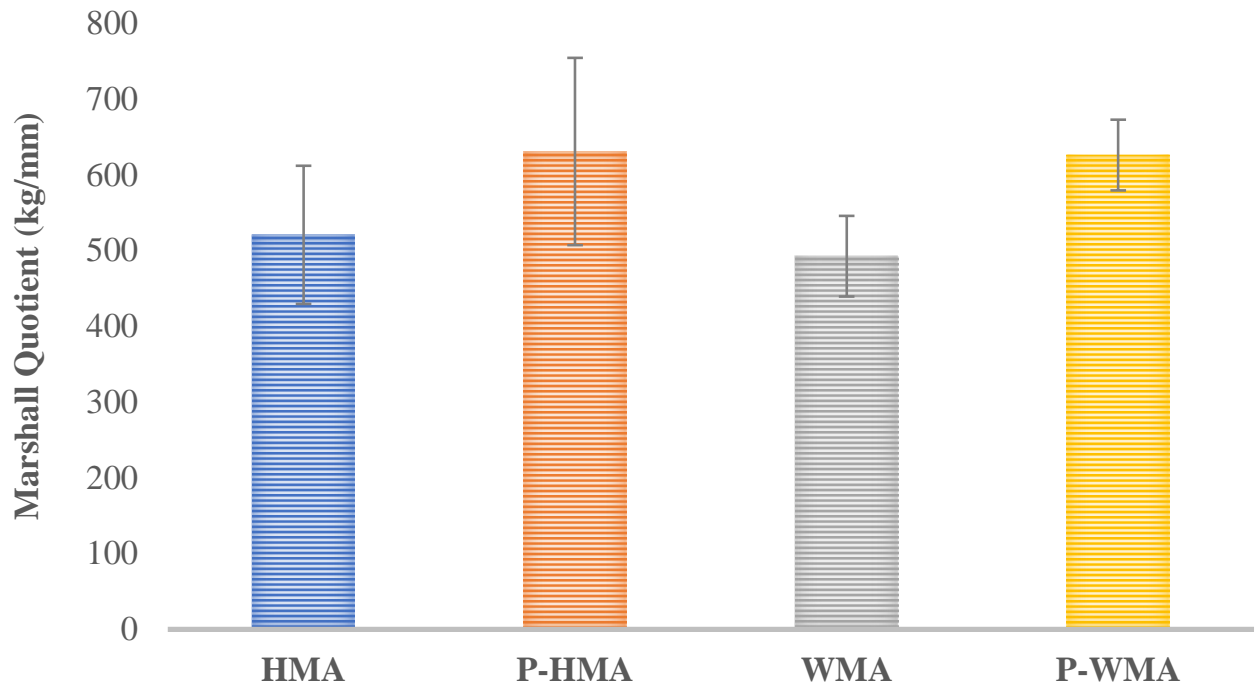

Fig. ) indicate that MQ values increased with the application of Superplast, which reveals higher resistance to rutting, especially in hot climatic areas. Where incorporating Superplast significantly improved the stiffness of both HMA, and WMA compared with the unmodified ones. The convention HMA presented a slightly higher stiffness than WMA (about 5\% more). However, the stiffness of both Superplastmodified mixtures (P-HMA and P-WMA) was almost the same. 
695

JES, Assiut University, Faculty of Engineering, Vol. 49, No. 5, Sept. 2021, pp. $679-703$

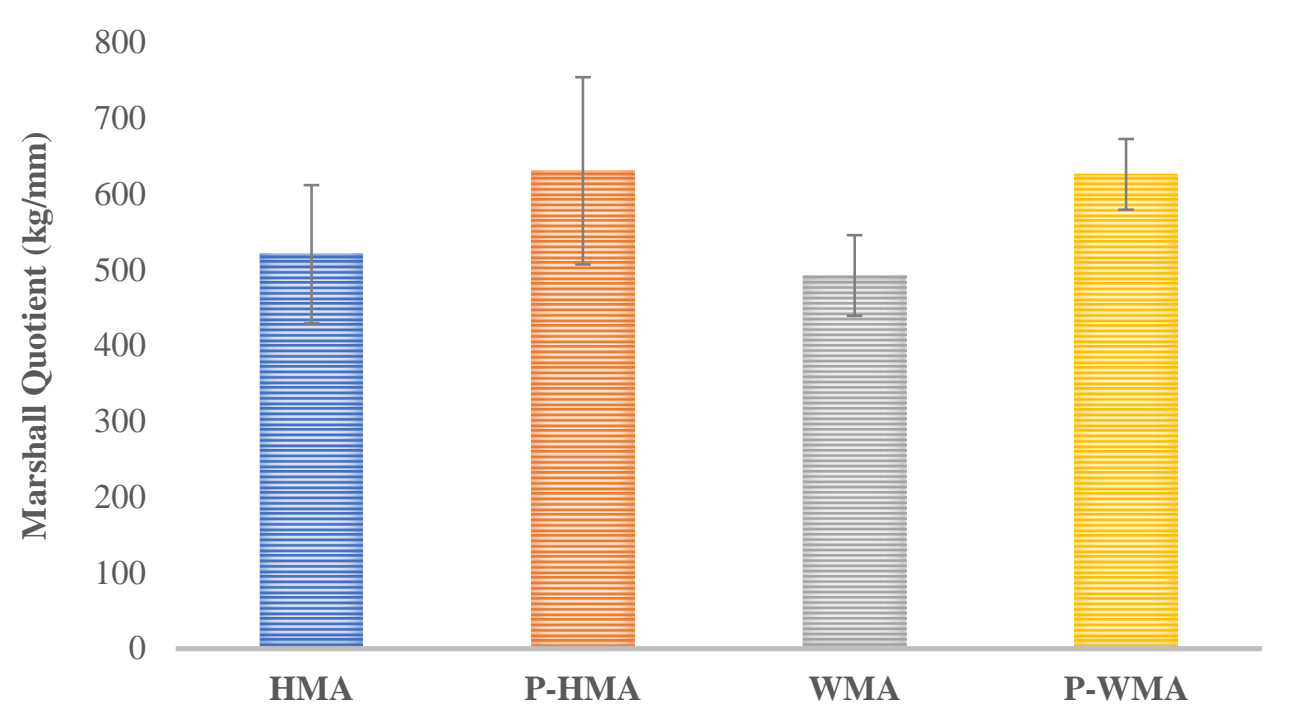

Fig. 8. Marshall quotient values for the unmodified and modified mixtures

\subsubsection{Moisture Damage Resistance Test}

The results of the modified Lottman test for both unmodified and Superplast-modified hot and warm mixtures are depicted in Fig. 9. In which the indirect tensile strength (ITS) values, for both dry and wet subgroups, as well as the calculated tensile strength ratio (TSR) are presented.

Based on Fig.9, incorporating Superplast improved the mean tensile strength (ITS) values for both HMA and WMA, with this increase being most pronounced for wet subgroups. Moreover, the attained improvement in WMA was significantly higher than that for HMA when incorporating Superplast. Compared with the unmodified WMA, Superplast-modified WMA (P-WMA) had an increase in the ITS values for dry and wet subgroups by $34.3 \%$ and $77.4 \%$, respectively. On the other hand, the ITS values associated with Superplast-modified HMA (P-HMA) were higher by $18 \%$ and $21.7 \%$ for dry and wet subgroups, respectively, in comparison with the conventional HMA.

Moreover, the tensile strength ratios (TSR) values also improved when incorporating Superplast for both HMA and WMA, as shown in Fig.9. Generally, warm mix asphalt mixtures exhibited higher TSR values than hot-mix asphalt, revealing higher resistance against moisture damage. However, Superplast-modified WMA (P-WMA) was the only mixture 
that satisfied the specification of Egyptian Code and (AASHTO T 283), i.e., more than $80 \%$ [52]. For the P-WMA mixture, TSR was above $100 \%$, which indicated that the mixture was insensitive to moisture. Similar results were reported by Peerapong Jitsangiam, Korakod Nusit, and Hamid Nikraz [ㄷ]].

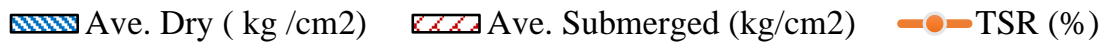

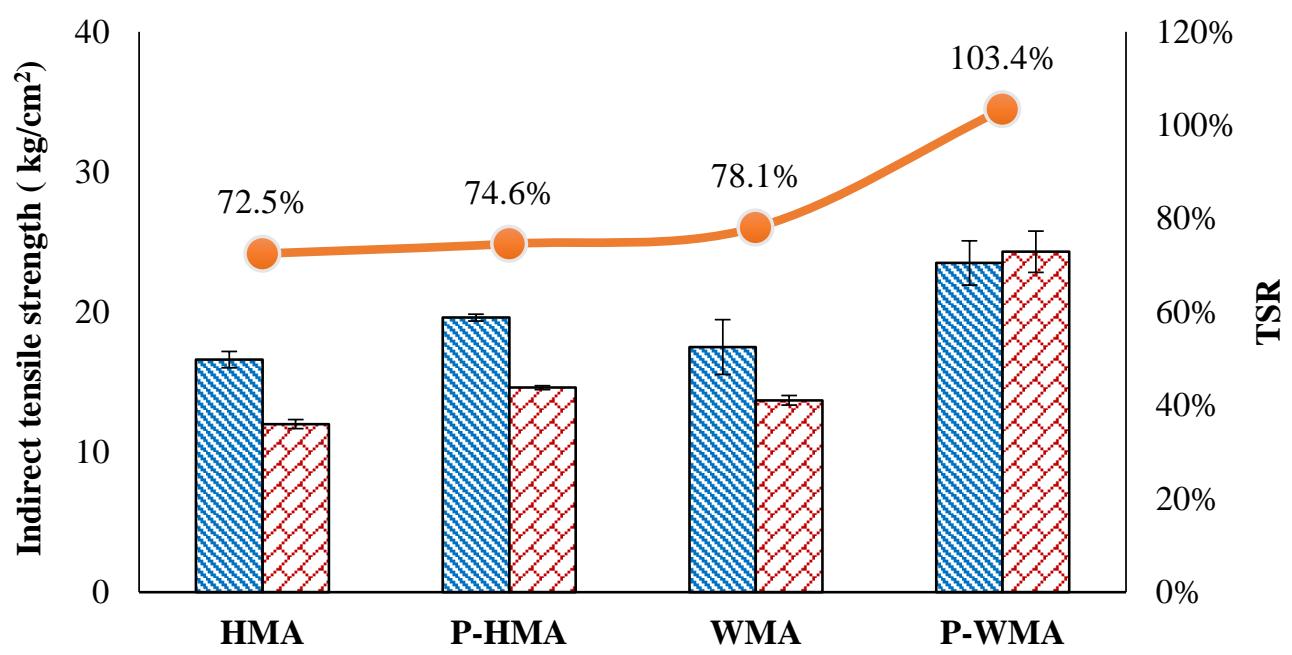

Fig. 9 Moisture damage results of the unmodified and modified mixtures

\subsubsection{Stripping susceptibility}

Fig. shows the Double Punch shear test results for the unmodified and Superplast-modified HMA and WMA mixtures. The double Punch test signifies the bonding strength between the aggregate and the binder. Results show that WMA had a little higher bonding strength than both convention HMA and Superplast-modified HMA. While incorporating Superplast significantly improved the shear stress value of WMA, it slightly enhanced the HMA's shear stress. Moreover, Superplastmodified WMA (P-WMA) had the superior shear stress value which is $49.4 \%, 43.8 \%$, and $37.5 \%$ higher than those of HMA, P-HMA, and WMA, respectively. 


\subsection{0}

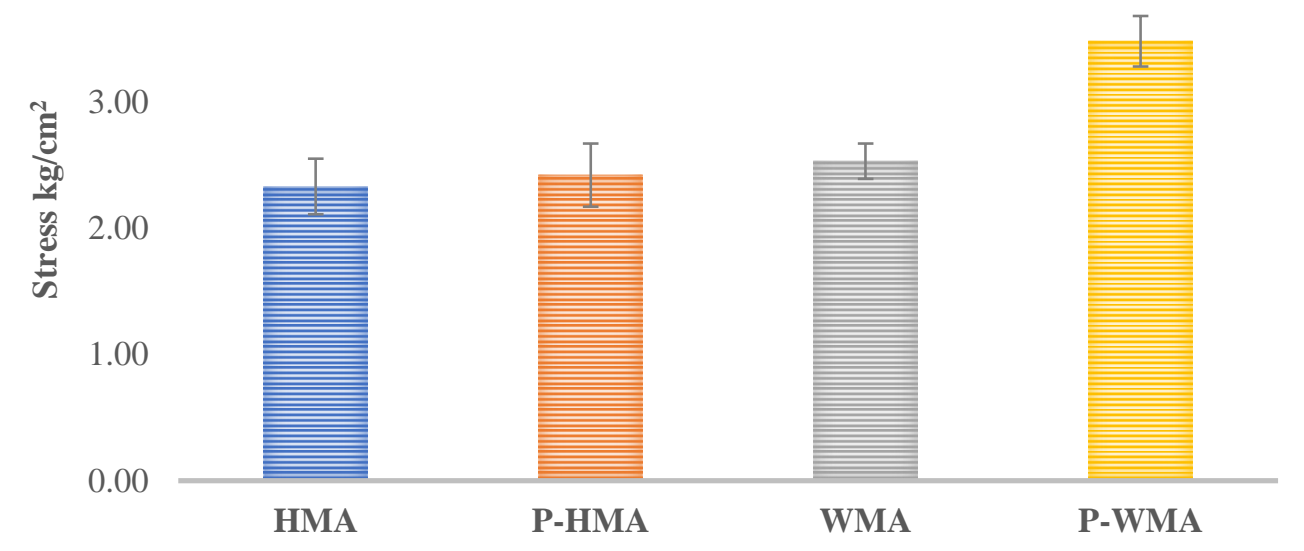

Fig. 10. Punching strength results for unmodified and modified mixtures

\section{Conclusions}

This study experimentally evaluated the performance of HMA and WMA mixtures when incorporating different percentages of low-cost polymer (Superplast). In the following, the main conclusions from the performance evaluation tests are presented:

- Generally, WMA mixtures exhibited higher resistance to moisture damage and stripping than HMA mixtures.

- While incorporating Superplast into HMA significantly improved the stiffness, it slightly enhanced the moisture damage resistance and stripping susceptibility.

- Incorporating Superplast into WMA significantly improved the stiffness, moisture damage resistance, and stripping susceptibility.

- Incorporating Superplast improved the adhesion between bitumen and aggregates, which ultimately led to an increase in the stiffness and moisture resistance of both HMA and WMA.

- While the stiffness of both Superplast-modified hot- and warmasphalt mixtures was almost the same, Superplast-modified WMA exhibited significantly higher moisture susceptibility and stripping resistance than that for Superplast-modified HMA. 
- Overall performance of Superplast-modified WMA mixtures is observed to be better compared to polymer modified HMA mixtures.

\section{Acknowledgments}

The authors acknowledge the support provided by Assiut University, Egypt, in carrying out this research.

\section{References}

[1] B. Kheradmand, R. Muniandy, L.T. Hua, R.B. Yunus, A. Solouki, An overview of the emerging warm mix asphalt technology, International Journal of Pavement Engineering 15(1) (2014) 79-94.

[2] N. Guo, Z. You, Y. Zhao, Y. Tan, A. Diab, Laboratory performance of warm mix asphalt containing recycled asphalt mixtures, Construction and Building Materials 64 (2014) 141-149.

[3] S. Capitão, L. Picado-Santos, F. Martinho, Pavement engineering materials: Review on the use of warm-mix asphalt, Construction and Building Materials 36 (2012) 1016-1024.

[4] M.H. Rashwan, Characterization of Warm Mix Asphalt (WMA) performance in different asphalt applications, Iowa State University, 2012.

[5] L. Robjent, W. Dosh, Warm-mix asphalt for rural county roads, Cold Regions Engineering 2009: Cold Regions Impacts on Research, Design, and Construction2009, pp. 438-454.

[6] W. Zhao, F. Xiao, S.N. Amirkhanian, B.J. Putman, Characterization of rutting performance of warm additive modified asphalt mixtures, Construction and Building Materials 31 (2012) 265-272.

[7] R. Vidal, E. Moliner, G. Martínez, M.C. Rubio, Life cycle assessment of hot mix asphalt and zeolite-based warm mix asphalt with reclaimed asphalt pavement, Resources, Conservation and Recycling 74 (2013) 101-114.

[8] R. West, C. Rodezno, G. Julian, D. Prowell, Engineering properties and field performance of warm mix asphalt technologies, National Cooperative Highway Research Program, Washington, DC, USA, NCHRP Final Report Project (0947A) (2014).

[9] R.B. Mallick, M. Tao, B.-L. Chen, K. O'sullivan, P. Cacciatore, Practical method to understand the effect of aggregate drying on the moisture content of hot-mix asphalt, Transportation research record 2208(1) (2011) 90-96.

[10] K. Kanitpong, N. Charoentham, S. Likitlersuang, Investigation on the effects of gradation and aggregate type to moisture damage of warm mix asphalt modified with Sasobit, International Journal of pavement engineering 13(5) (2012) 451458.

[11] A. Ali, A. Abbas, M. Nazzal, A. Alhasan, A. Roy, D. Powers, Workability evaluation of foamed warm-mix asphalt, Journal of materials in civil engineering 26(6) (2014) 04014011. 
[12] B. Şengöz, A. Topal, C. Gorkem, Evaluation of moisture characteristics of warm mix asphalt involving natural zeolite, Road materials and pavement design 14(4) (2013) 933-945.

[13] W. Barthel, J. Marchand, M. Von Devivere, Warm asphalt mixes by adding a synthetic zeolite, PROCEEDINGS OF THE 3RD EURASPHALT AND EUROBITUME CONGRESS HELD VIENNA, MAY 2004, 2004.

[14] B.D. Prowell, G.C. Hurley, E. Crews, Field performance of warm-mix asphalt at national center for asphalt technology test track, Transportation Research Record 1998(1) (2007) 96-102.

[15] J. Yan, Y. Cao, T. Zhu, M. Cai, Z. Cao, W. Huang, Q. Dong, Shanghai experience with warm mix asphalt, Paving Materials and Pavement Analysis2010, pp. 97-102.

[16] Y.-R. Kim, J. Zhang, H. Ban, Moisture damage characterization of warm-mix asphalt mixtures based on laboratory-field evaluation, Construction and Building Materials 31 (2012) 204-211.

[17] C. Bindu, M.S. Joseph, P. Sibinesh, S. George, S. Sivan, Performance evaluation of warm mix asphalt using natural rubber modified bitumen and cashew nut shell liquid, International Journal of Pavement Research and Technology 13(4) (2020) 442-453.

[18] M.J. Ayazi, A. Moniri, P. Barghabany, Moisture susceptibility of warm mixedreclaimed asphalt pavement containing Sasobit and Zycotherm additives, Petroleum Science and Technology 35(9) (2017) 890-895.

[19] A. Vaitkus, D. Čygas, A. Laurinavičius, Z. Perveneckas, Analysis and evaluation of possibilities for the use of warm mix asphalt in Lithuania, The Baltic Journal of Road and Bridge Engineering 4(2) (2009) 80-86.

[20] S.D. Diefenderfer, K.K. McGhee, B.M. Donaldson, Installation of warm mix asphalt projects in Virginia, Virginia Transportation Research Council, 2007.

[21] R. West, Field testing of warm mix asphalt, Presentation at the Warm Mix Asphalt \& Recycling Symposium, Sacramento, CA, 2009.

[22] Z. Arega, A. Bhasin, A. Motamed, F. Turner, Influence of warm-mix additives and reduced aging on the rheology of asphalt binders with different natural wax contents, Journal of Materials in Civil Engineering 23(10) (2011) 1453-1459.

[23] V. Punith, F. Xiao, S.N. Amirkhanian, Effects of moist aggregates on the performance of warm mix asphalt mixtures containing non-foaming additives, Journal of Testing and Evaluation 39(5) (2011) 847-857.

[24] A. Ali, A. Abbas, M. Nazzal, A. Alhasan, A. Roy, D. Powers, Effect of temperature reduction, foaming water content, and aggregate moisture content on performance of foamed warm mix asphalt, Construction and Building Materials 48 (2013) 1058-1066.

[25] J.D. Doyle, I.L. Howard, Rutting and moisture damage resistance of high reclaimed asphalt pavement warm mixed asphalt: loaded wheel tracking vs. conventional methods, Road Materials and Pavement Design 14(sup2) (2013) $148-172$. 
[26] S. Kim, J. Park, S. Lee, K.W. Kim, Performance of modified WMA Mixtures prepared using the same class pg binders of HMA mixtures, Journal of Testing and Evaluation 42(2) (2014) 347-356.

[27] H. Rondón-Quintana, J. Hernández-Noguera, F. Reyes-Lizcano, A review of warm mix asphalt technology: Technical, economical and environmental aspects, Ingeniería e Investigación 35(3) (2015) 5-18.

[28] R.T. Abd El-Hakim, J. Epps, A. Epps Martin, E. Arámbula-Mercado, Laboratory and field investigation of moisture susceptibility of hot and warm mix asphalts, International Journal of Pavement Engineering (2019) 1-10.

[29] Y. Edwards, U. Isacsson, Wax in bitumen, Road Materials and Pavement Design 6(4) (2005) 439-468.

[30] N.I.M. Yusoff, D. Mounier, G. Marc-Stéphane, M.R. Hainin, G.D. Airey, H. Di Benedetto, Modelling the rheological properties of bituminous binders using the 2S2P1D Model, Construction and Building Materials 38 (2013) 395-406.

[31] N. Bala, M. Napiah, I. Kamaruddin, Effect of nanosilica particles on polypropylene polymer modified asphalt mixture performance, Case studies in construction materials 8 (2018) 447-454.

[32] H. Rooholamini, R. Imaninasab, M. Vamegh, Experimental analysis of the influence of SBS/nanoclay addition on asphalt fatigue and thermal performance, International Journal of Pavement Engineering 20(6) (2019) 628-637.

[33] G. Moussa, A. Abdel-Raheem, T. Abdel-Wahed, Investigating the moisture susceptibility of asphalt mixtures modified with high-density polyethylene, JES. Journal of Engineering Sciences 48(5) (2020) 765-782.

[34] G.S. Moussa, A. Abdel-Raheem, T. Abdel-Wahed, Effect of Nanoclay Particles on the Performance of High-Density Polyethylene-Modified Asphalt Concrete Mixture, Polymers 13(3) (2021) 434.

[35] Y.M. Alghrafy, E.-S.M. Abd Alla, S.M. El-Badawy, Rheological properties and aging performance of sulfur extended asphalt modified with recycled polyethylene waste, Construction and Building Materials 273 (2021) 121771.

[36] A.M. Azam, S.M. El-Badawy, R.M. Alabasse, Evaluation of asphalt mixtures modified with polymer and wax, Innovative Infrastructure Solutions 4(1) (2019) 43.

[37] H.K. Zubeck, L. Raad, S. Saboundjian, G. MinassianIl, P. John Ryer §, Workability and performance of polymer-modified asphalt aggregate mixtures in cold regions, International Journal of Pavement Engineering 4(1) (2003) 2536.

[38] S. Wu, L. Montalvo, Repurposing waste plastics into cleaner asphalt pavement materials: A critical literature review, Journal of Cleaner Production (2020) 124355.

[39] H. Kim, S.-J. Lee, S.N. Amirkhanian, Effects of warm mix asphalt additives on performance properties of polymer modified asphalt binders, Canadian Journal of Civil Engineering 37(1) (2010) 17-24.

[40] A. Buddhala, Z. Hossain, N.M. Wasiuddin, M. Zaman, A. Edgar, Effects of an amine anti-stripping agent on moisture susceptibility of sasobit and aspha-min mixes by surface free energy analysis, Journal of Testing and Evaluation 40(1) (2012) 91-99. 
[41] M. Arabani, H. Roshani, G.H. Hamedi, Estimating moisture sensitivity of warm mix asphalt modified with zycosoil as an antistrip agent using surface free energy method, Journal of Materials in Civil Engineering 24(7) (2012) 889-897.

[42] F. Xiao, W. Zhao, T. Gandhi, S.N. Amirkhanian, Influence of antistripping additives on moisture susceptibility of warm mix asphalt mixtures, Journal of Materials in Civil Engineering 22(10) (2010) 1047-1055.

[43] A. Diab, Z. You, H. Wang, Rheological evaluation of foamed WMA modified with nano hydrated lime, Procedia-Social and Behavioral Sciences 96 (2013) 2858-2866.

[44] A. Kavussi, L. Hashemian, Laboratory evaluation of moisture damage and rutting potential of WMA foam mixes, International Journal of Pavement Engineering 13(5) (2012) 415-423.

[45] ASTM D5 / D5M-20, Standard Test Method for Penetration of Bituminous Materials, ASTM International, West Conshohocken, PA, , 2020.

[46] ASTM D36 / D36M-14(2020), Standard Test Method for Softening Point of Bitumen (Ring-and-Ball Apparatus), ASTM International, West Conshohocken, PA, 2020.

[47] Shorouk Chemical Company, 2021. http://bitu-tech.com/index.php?lang=ar. (Accessed 15/6/2021 2021).

[48] A. D6927, Standard Test Method for Marshall Stability and Flow of Asphalt Mixtures, STM International, West Conshohocken, PA, 2015.

[49] R.A. Jimenez, Testing for debonding of asphalt from aggregates, Transportation Research Record 515, TRB, National Research Council, Washington, D.C., pp. 1-17 (1974).

[50] H. Wen, S. Bhusal, X. Li, Double punch test: simple performance test to evaluate the fatigue and rutting potential of asphalt concrete, Journal of materials in civil engineering 25(5) (2013) 645-652.

[51] H.a.B.N.R. Center, Egyptian Code for Urban and Rural Roads, Road Material and its Tests, Table 2-1-1., 2008, p. p. 101.

[52] ECP, Egyptian Code for Urban and Rural Roads - Part 4: Road Material and its Tests, Egypt, 2008.

[53] G. Shafabakhsh, M. Aliakbari Bidokhti, H. Divandari, Evaluation of the performance of SBS/Nano-A12O3 composite-modified bitumen at high temperature, Road Materials and Pavement Design (2020) 1-15.

[54] M. Panda, M. Mazumdar, Engineering properties of EVA-modified bitumen binder for paving mixes, Journal of materials in civil engineering 11(2) (1999) 131-137.

[55] S. Tapkin, Improved asphalt aggregate mix properties by portland cement modification, PROCEEDINGS OF THE PAPERS SUBMITTED FOR REVIEW AT 2ND EURASPHALT AND EUROBITUME CONGRESS, HELD 20-22 SEPTEMBER 2000, BARCELONA, SPAIN. BOOK 2-SESSION 2, 2000.

[56] S. Tapkın, A. Çevik, Ü. Uşar, Prediction of Marshall test results for polypropylene modified dense bituminous mixtures using neural networks, Expert Systems with Applications 37(6) (2010) 4660-4670. 
[57] A. Standard, Standard test method for marshall stability and flow of asphalt mixtures, West Conshohocken, PA (2015).

[58] R.A. Jimenez, Evaluation of methods to control debonding, FHWA, 1988.

[59] B.M. Kiggundu, F.L. Roberts, Stripping in HMA Mixtures: State-of-the-Art and Critical Review of Test Methods, in: T. Auburn University. National Center for Asphalt (Ed.) 1988.

[60] R.K. Hamdan, S.I. Sarsam, Impact of rejuvenators type on physical properties of aged asphalt cement, Civil Engineering Journal 5(9) (2019) 2058-69.

[61] H.H. Joni, R.H.A. Al-Rubaee, M.K. Shams, Assessment of Durability Properties of Reclaimed Asphalt Pavement Using Two Rejuvenators: Waste Engine Oil and Asphalt Cement (60-70) Penetration Grade, IOP Conference Series: Materials Science and Engineering 1090(1) (2021) 012001.

[62] X.X. Wei, K.T. Chau, Finite solid circular cylinders subjected to arbitrary surface load. Part II - Application to double-punch test, International Journal of Solids and Structures 37(40) (2000) 5733-5744.

[63] A. Institute, Determining lab mixing and compaction temperatures for binders, 2017. http://www.asphaltinstitute.org/engineering/determining-lab-mixingcompaction-temperatures-binders/. (Accessed December 1 2020).

[64] M. Arabani, S.A. Tahami, M. Taghipoor, Laboratory investigation of hot mix asphalt containing waste materials, Road Materials and Pavement Design 18(3) (2017) 713-729.

[65] P. Jitsangiam, K. Nusit, H. Nikraz, An Evaluation of Moisture Damage Resistance of Asphalt Concrete based on Dynamic Creep Characteristics, KSCE Journal of Civil Engineering 23(4) (2019) 1610-1616. 


\section{التحقيق في أداء خلطات الأسفلت الساخنة والدافئة المعدلة باستخدام السوبربلاست}

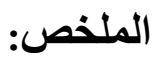

تعد أضرار الرطوبة والتعرية من أكثر العيوب انتشارًا في كل من الخلطات الاسفلتية

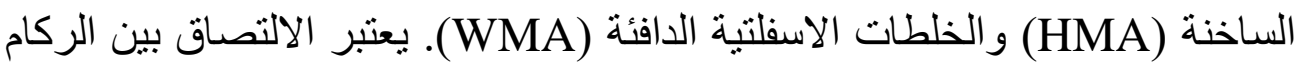

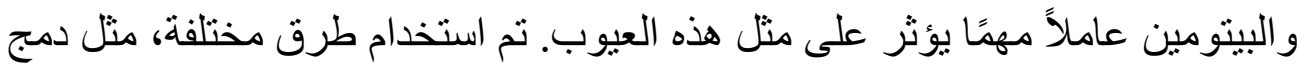

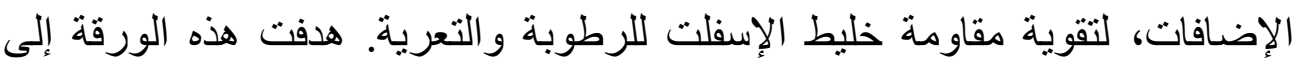
التحقيق التجريبي في تأثير اضافة مادة بوليمر منخفضة التكلفة السوبربلاست (Superplast)

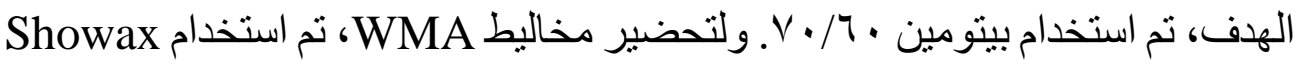
بنسب r و س وع و ه و ؟\% من وزن البيتومين. تم تحضير الخلطات البوليمرية المعدلة

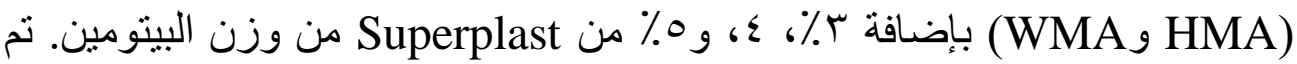

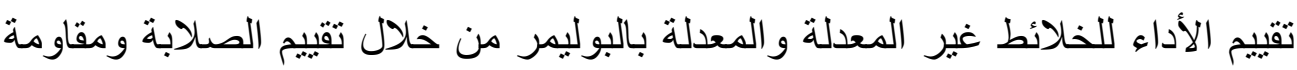
تلف الرطوبة وقابلية التجريد عبر اختبارات Marshall و Double و Dottman و Punching أظهرت النتائج أن دمج Superplast أدى إلى تحسين الالتصاق بين

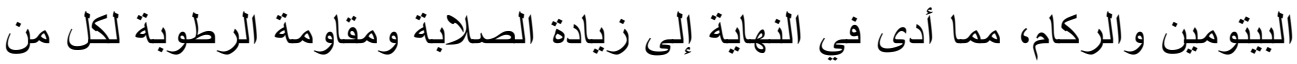
الخلطات الاسفلتية الساخنة و الدافئة. علاوة على ذلك، لوحظ أن الأداء العام للخلطات الاسفلتية الدافئة المعدلة بال Superplast كان الأفضل مقارنة بباقي الخلطات الاسفلتية

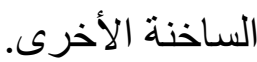

